\title{
Reflexões sobre a inserção profissional de assistentes sociais na conciliação de conflitos e mediação familiar
}

\author{
Reflections on the professional insertion \\ of social assistants in conciliation of \\ conflicts and family mediation
}

\author{
Claudio Horst ${ }^{a}$ \\ (D) https://orcid.org/0000-0002-2226-4520 \\ Emilly Marques Tenoriob \\ (1) https://orcid.org/0000-0002-3922-0495
}

\begin{abstract}
Resumo: O presente artigo analisa a inserção da/o assistente social na atividade de conciliação de conflitos/mediação familiar. Aponta duas questões centrais que, a nosso ver, assinalam a (re)atualização do conservadorismo: I) o confronto aos fundamentos ético-políticos profissionais e II) a concepção do trabalho com famílias. Assim, a atuação profissional pende para práticas conciliatórias e neoconservadoras, na defesa da neutralidade, alijadas da luta de classes e das opressões, a partir de uma abordagem sistêmica das famílias.
\end{abstract}

Palavras-chave: Serviço Social. Conciliação de Conflitos. Mediação Familiar.

\begin{abstract}
This article analyzes the insertion of the social worker in the activity of conciliation of conflicts/family mediation. It points to two central issues that, in our view, point to the (re) update of conservatism: I) confrontation with professional ethicalpolitical foundations and II) the conception of work with families. The professional insertion in this activity depends on conciliatory and neoconservative practices, on the defense of neutrality, from class struggle and oppression, based on a systemic approach of families.
\end{abstract}

Keywords: Social Worker. Conflict Resolution. Conflict Mediation. 


\section{Introdução}

A

s transformações societárias que marcam o tempo presente afetam diretamente todo o conjunto da sociabilidade — incluindo o sistema judiciário - e incidem diretamente sobre as profissões. Netto (1996) já nos alertou sobre a crescente segmentação no mercado de trabalho das/dos assistentes sociais que acarretaria no estreitamento tanto das "fronteiras" quanto dos conflitos no âmbito das atribuições profissionais. A conciliação de conflitos e a mediação familiar ${ }^{1}$ aparecem como uma proposta da área sociojurídica ${ }^{2}$ como uma das alternativas ao modelo adversarial consolidado nas varas de família. Encampada como uma nova frente de intervenção, é normatizada pelo Conselho Nacional de Justiça (CNJ).

Conforme sabemos, o Judiciário e o Direito ainda são vistos como espaços neutros, de garantia de direitos e resolução de conflitos, de comprovação e busca "da verdade", entretanto, escamoteia injustiças e opressões, sendo essa fetichização necessária para sua perpetuação.

Nesse sentido, é preciso estarmos atentos às "velhas" demandas, travestidas "do novo". Isso porque a tendência é que as discussões em torno da direção crítica assumida pela profissão - e aqueles que se opõem a tal direção — não apareçam de forma aberta. Conforme chamou-nos a atenção Netto, nos últimos anos não tivemos questionamentos diretos e significativos ao Projeto Ético-Político, pelo contrário, a estratégia “[...]consiste em proclamá-lo e invocá-lo como se fora um projeto cujo pluralismo não tem fronteiras e que, portanto, comporta ilimitadas possibilidades de concretização teórica e prática" (Netto, 2016, p. 66).

É a partir do impacto das transformações societárias no âmbito do Judiciário que conseguiremos compreender a demanda pela inserção na

1 A conciliação de conflitos e a mediação familiar aparecem, ao lado de outras inovações, como formas alternativas ao modelo tradicional de "solução" das lides pelo Poder Judiciário. Afim de evitar a repetição de ambos os termos utilizaremos daqui para frente somente o termo "mediação familiar".

2 Ainda hoje ocorrem debates sobre se o Sociojurídico se constituiria "área", "campo", "esfera" ou "sistema". Concordamos com Borgianni e adotaremos no presente texto "área sociojurídica". Ver Borgianni (2013). 
mediação familiar. E assim, localizá-la como uma estratégia que pende para o fortalecimento do Estado capitalista (Hillesheim, 2016). Conforme demonstrou Hillesheim (2016), a busca pela resolução de conflitos de maneira mais célere, especialmente por Meio Alternativo de Resolução de Conflitos (MARC) de onde surge a resolução n. 125 do Conselho Nacional de Justiça (que define o papel e o lugar do/a mediador/a de conflitos):

Provocou e vem provocando mudanças no âmbito do sistema de justiça que expressam como as formas jurídicas se conectam às estruturas sociais. Nessa direção é preciso demarcar o avanço da perspectiva privatizante nas atividades jurisdicionais, o que também se observa nesse processo de reorganização para implementar a Política Judiciária Nacional de Tratamento Adequado dos Conflitos de Interesses (PJNTACI) (Hillesheim, 2016, p. 513).

A demanda pelo debate sobre mediação familiar surgiu por parte de assistentes sociais inseridas/os na área sociojurídica que vêm sendo demandadas ou que optaram por realizar tal atividade. Conforme aponta o relatório analítico do CRESS/SP, constatou-se a existência de um segmento da profissão que "considera a 'mediação de conflitos' ora como uma atribuição profissional e ora como possibilidade de capacitação em instrumentalidade de trabalho" (CRESS/SP, 2016, p. 59)3. É importante salientarmos desde já que nossa reflexão não visa problematizar a atividade da mediação, ou a profissão do mediador de conflitos em si, que exigiria outra direção na reflexão ${ }^{4}$, mas refletir em torno dos problemas quando uma profissão como o Serviço Social assume para si tal tarefa.

3 Cabe ressaltar que tal discussão vem sendo realizada no âmbito do conjunto CFESS/CRESS desde 2014. No 46 Encontro, em 2017, a deliberação continua e é acrescida de ações práticas aliadas à permanência do debate e do posicionamento com a deliberação 7: "Desenvolver ações políticas em relação à incompatibilidade da atuação da/o assistente social em ações de conciliação e mediação de conflitos, aprofundar o debate e elaborar posicionamento em relação à atuação da/o assistente social em outras práticas de autocomposição de conflitos (justiça restaurativa e ações congêneres) propostas pelo CNJ e outros órgãos".

4 Para uma leitura crítica e mais ampla em torno da conciliação/mediação indicamos a Tese de Hillesheim (2016) e o artigo de Parizotto (2018) que apontam as problemáticas em torno 
Metodologicamente, realizamos revisão de literatura e pesquisa bibliográfica em torno dos posicionamentos construídos pelo conjunto CFESS/ CRESS e de pesquisas realizadas sobre a inserção profissional nessa área. Entendemos que enfrentar a presente discussão é tarefa urgente e necessária, principalmente, num cenário de retomadas de perspectivas neoconservadoras na profissão.

\section{Exercício profissional no sociojurídico e novas demandas}

Sem isolar o Serviço Social das determinações e relações sociais que lhe conformam - relações capitalistas de produção, especificadamente a partir do capitalismo monopolista - entendemos que o exercício profissional ocorre na materialização de um processo de trabalho que têm como objeto as diferentes expressões da "questão social". O significado social da profissão - como inscrita na divisão social e técnica do trabalho, nos remete a compreendê-la como essencialmente política, ainda que conforme nos adverte Iamamoto (2013, p. 134), apareça sob o manto “[...] de atividades dispersas, descontínuas, de caráter filantrópico, marcadas pelo fornecimento de 'benefícios' sociais”.

Nessa direção, para compreendermos os dilemas enfrentados pela profissão nesse espaço é necessário localizarmos as mudanças pela qual o judiciário vem passando, e que tensionam o exercício profissional mediado pelo projeto profissional. Conforme apontou Hillesheim (2016) a mudança nos modos de "resolver" conflitos no âmbito do judiciário, visando tornar a justiça célere e qualificar a ação jurisdicional perpassa pela defesa da mudança de um paradigma que defende a substituição da litigiosidade em detrimento das posturas conciliatórias. Conforme apontou o autor, é a própria resolução n. 125 do CNJ que norteia as ações jurídico-legais que passaram

dessa tendência. Partilhamos de tais posicionamentos, mas no presente texto analisaremos o impacto dela para uma profissão comprometida com valores emancipatórios. 
a ser planejadas e implementadas visando estimular a adoção de métodos alternativos de resolução de conflitos (MARC).

Essa articulação, para a construção de um pensamento único em torno das formas de resolução dos conflitos, cuja tônica é na verdade o encobrimento das causas estruturais desses conflitos, em especial a apropriação privada dos meios de produção e da riqueza produzida, é de extrema importância para a perpetuação das relações de dominação. [...] Se é necessário provocar mudanças objetivas - na estruturação e dinâmica do poder judiciário sob uma ótica gerencial - e subjetivas - no convencimento ideológico dos que o compõem - para que tal poder seja "modernizado" e esteja em "sintonia" com "novos tempos", é também necessário que a sociedade em geral assimile a perspectiva adotada, cuja teleologia ou projeção tem como um dos pilares a cultura da pacificação social, a cultura da conciliação (Hillesheim, 2016, p. 485, grifos nossos).

Nessa direção, a conciliação/mediação entra no bojo das alternativas que se apresentam para "desafogar" o Judiciário na contramão do que defendemos: voluntariado 5 , terceirização, banco de peritos/as, convênios com o Executivo ou parcerias público-privadas, em detrimento de concurso público e formação continuada de corpo técnico especializado para o atendimento às demandas sociais judicializadas. Leitura, que em última análise, possibilitará demonstrar que a atividade de mediação não amplia "oportunidades" para assistentes sociais frente ao desemprego - justificativa comum nas produções. Tal alternativa articula-se ainda, com áreas do conhecimento que possuem fundamentos conservadores

Como as teorias psicológicas comportamentais, que têm seu uso mencionado em outras experiências de operacionalização dos MARC, de modo que as questões subjetivas dos litigantes é objeto de manipulação nas audiências de conciliação com vistas à tabulação de acordos (Hillesheim, 2018, p. 495).

5 Recentemente o CRESS/ES, 17a Região, elaborou um termo de Orientação profissional sobre a "Prática de voluntariado realizado por assistentes sociais com objetivo de adquirir experiência profissional”, disponível no site: www.cress-17.org.br 
De acordo com Netto (2011), a psicologização da vida social além de depositar nos indivíduos as responsabilidades por suas mazelas, também se utiliza dos espaços das instituições para causar a impressão de atendimento personalizado, no qual as demandas estariam sendo atendidas:

[...] o potencial legitimador da ordem monopólica contido na psicologização ultrapassa de longe a imputação ao indivíduo da responsabilidade do seu destino social; bem mais que este efeito, por si só relevante, implica um tipo novo de relacionamento "personalizado" entre ele e instituições próprias da ordem monopólica que, se não se mostram aptas para solucionar as refrações da "questão social" que o afetam, são suficientemente lábeis para entrelaçar, nos "serviços" que oferecem e executam, desde a indução comportamental até os conteúdos econômico-sociais mais salientes da ordem monopólica — num exercício que se constitui em verdadeira "pedagogia" psicossocial, voltada para sincronizar as impulsões individuais e os papéis sociais propiciados aos protagonistas (Netto, 2011, p. 42).

Conforme sabemos, o trabalho com indivíduos e famílias constitui parte do trabalho profissional. No entanto, ao entender as demandas postas pelos sujeitos como expressões das necessidades humanas impedidas de serem concretizadas numa sociedade de classes, a perspectiva teórico e metodológica de tal leitura não reconhece como possível qualquer resposta profissional voltada para a tentativa de "reduzir antagonismos e agregar estabilização emocional”, para citarmos um exemplo do que prevê a formação de mediadores ${ }^{6}$.

Fávero (2013) realiza um resgate sobre a inserção do Serviço Social no Judiciário e nos convida a refletir: "Qual perspectiva de justiça social e de direitos norteia esse fazer profissional?”. Consideramos que tal provocação é pertinente na análise da temática em voga. Trata-se de uma nova atividade ou uma velha demanda institucional que se reatualiza na busca pelo reajuste

6 Tem ainda como objetivos: "o estímulo às partes para que estas tenham mais estabilidade familiar e em razão disto: i) Reduzir antagonismos e agregar estabilização emocional; ii) Aumentar satisfação com procedimentos jurídicos e seus resultados; e iii) Aumentar índice de cumprimento de decisões judiciais" (Conselho Nacional de Justiça, 2015). 
familiar e pela "paz social"? Pela amenização de conflitos e apagamentos das contradições? Entendemos que "falar em reprodução das relações sociais na sociedade capitalista é falar em contradições e antagonismos, o que nos leva, já de início, à consideração de que o Direito, também ele, é atravessado por essas negatividades e torna-se reprodutor mesmo dessas relações" (Borgianni, 2013, p. 421).

A crítica lukacsiana ao Direito aponta que o mesmo se apresenta como um sistema fechado, lógico, estático frente às diferenciações sociais, "um sistema coeso, coerente, que exclui contradições” (Lukács, 2013, p. 239). Propõe-se a dirimir conflitos e antagonismos sociais, o que se constitui uma "ilusão jurídica”, já que autonomiza tal complexo das mediações materiais e políticas, sendo seu ordenamento ancorado "na vontade da respectiva classe dominante de ordenar a práxis social em conformidade com suas intenções” (Lukács, 2013, p. 240).

A necessidade sócio-histórica do Direito é reforçada por Sartori (2014), ao demonstrar que interesses divergentes, que poderiam ter tratamentos violentos, são reduzidos ao caráter homogeneizador da esfera jurídica, conflitos sociais são transformados em demandas jurídicas e as relações de produção se revestem juridicamente, reportadas e avaliadas por "especialistas”, fixadas em "fórmulas jurídicas" (Lukács, 2013).

Portanto, como considerar o Judiciário como um espaço neutro, "imparcial” que possibilita a resolução de conflitos sem impositividade e relações de poder? É nesse espaço contraditório que o Serviço Social compõe, ao lado de outras profissões, a equipe de especialistas do Judiciário. Nesse sentido, Borgianni (2013) nos chama atenção em relação ao desafio posto no cotidiano do exercício profissional de não assumirmos demandas e práticas institucionais sem questioná-las, principalmente num cenário de aumento da judicialização das expressões da "questão social", em que as/os profissionais são convocadas a realizar estudos sociais a partir dos objetivos postos pela instituição.

Nesse sentido, é preciso refletir sobre as requisições conservadoras que vêm sendo colocadas no âmbito do sociojurídico e que podem fazer uso do trabalho cotidiano da/do assistente social e conforme Borgianni nos alerta: 
A partir das expressões cotidianas mais singulares e aparentemente desprovidas de mediações sociais concretas é que os assistentes sociais que atuam nessa área têm que operar e trabalhar para reverter a tendência reprodutora da dominação, da culpabilização dos indivíduos e da vigilância de seus comportamentos (Borgianni, 2013, p. 423).

É a partir de tais desafios colocados para a área sociojurídica que apontaremos elementos que caracterizam a mediação familiar com vistas a contribuir para que assistentes sociais - frente a necessidade e possibilidade de optar pela direção social — reflitam sobre as referências teórico-metodológicas e ético-políticas necessárias para uma prática sintonizada com as necessidades históricas dos/as trabalhadores/as, na direção do projeto profissional.

\section{As defesas pela inserção profissional na conciliação e mediação de conflitos}

De acordo com a Lei de Mediação (Lei n. 13.140, de 26 de junho de 2015): "Considera-se mediação a atividade técnica exercida por terceiro imparcial ${ }^{7}$ sem poder decisório, que, escolhido ou aceito pelas partes, as auxilia e estimula a identificar ou desenvolver soluções consensuais para a controvérsia".

Cabe destacar que, no que tange à leitura da profissão, a mediação é compreendida ora como uma atividade, ora como uma técnica, e/ou como mais um espaço sócio-ocupacional que atua sobre o conflito familiar (Toni, 2017). O objeto da mediação familiar é o próprio conflito familiar e o direito de família, ou seja, conflitos resultantes das relações familiares. Nesse sentido, a mediação familiar judicializada ${ }^{8}$ é acionada como um dos

Já o artigo $2^{\circ}$ dispõe sobre os princípios que deverão orientar a mediação: I — imparcialidade do mediador; II — isonomia entre as partes; III — oralidade; IV — informalidade; V — autonomia da vontade das partes; VI — busca do consenso; VII — confidencialidade; VIII — boa-fé.

8 Cabe lembrar que a Lei da Mediação estabelece regras para a mediação extrajudicial ou pré-judicial. Remetendo a uma situação que antecede a judicialização, cuja mediação familiar pode evitar. Mediadores voluntários geralmente se encarregam dessa função. 
recursos possíveis para ajudá-los a "resolver". A finalidade de tal atividade pode ser resumida na tentativa de preservar os relacionamentos, os laços de parentalidades, sempre a partir das decisões tomadas diretamente pelos sujeitos que vivenciam os conflitos. Além disso, pode ser visto como um espaço que visa à garantia de direitos (quando a/o profissional encaminha para a rede de serviços) (Toni, 2017; Fávero; Mazuelos, 2010).

Conforme chama atenção Toni (2017), no que tange à atuação do mediador, a mesma se vincula aos distintos fundamentos teórico-metodológicos da mediação ${ }^{9}$. Ao mediador, conforme também aponta a legislação, cabe facilitar o processo de comunicação sem conduzir para respostas que considere a melhor saída. Afinal, a partir dos princípios da imparcialidade e autonomia, "não cabem a este influenciar e decidir sobre as partes" (ibid., p. 49).

Tal experiência teve início no Brasil na década de 1980. Inicialmente com enfoque em questões trabalhistas, comerciais e empresariais. Desde os anos 1990 o enfoque passou a ser também nas questões familiares. No que tange aos debates familiares, a ideia é a responsabilização dos protagonistas como capazes de elaborar acordos, com foco nas questões como separação (divórcio), adoção, guarda, cuidado com idoso, herança etc. Conforme apontou a Nota Técnica do CRESS/SP (2016), no âmbito da categoria, a realização e a defesa pela mediação aparecem majoritariamente nas instituições que compõem o sistema de garantia de direitos, com destaque para o judiciário. Nem sempre como uma impositividade, mas por vezes sugerida/implementada por opção da própria equipe profissional ${ }^{10}$.

Em um levantamento inicial acerca da formação ofertada para executar a mediação de conflitos, identificamos a variedade de carga-horária, preços, modalidades (on-line, presencial, semipresencial, com e sem estágio), porém em comum, uma abordagem sistêmica das famílias. Os temas abordados

9 A autora realiza um balanço dos modelos teórico-metodológicos da mediação, e defende que a mediação waratiana ou transformadora é a que mais se aproxima do projeto ético-político da profissão (Toni, 2017). Entendimento do qual discordamos.

10 Por exemplo, no Trabalho de Conclusão de Curso apresentado no curso de graduação em Serviço Social da Universidade Federal de Ouro Preto pela aluna Joyce Dias, intitulado: "O Serviço Social e a Mediação de Conflitos no CEJUS/BH: desprofissionalização do assistente social?” (2018). 
na Mediação Familiar da Escola são Conceito de Família, Breve histórico da Mediação de Família, Preceitos básicos sobre a Teoria Sistêmica; Divórcio — dimensões psicológicas do processo de divórcio, a Guarda (tipos de guarda), Genograma; Ferramentas da Mediação de Família e Competências emocionais. De acordo com o curso do CNJ, ratifica-se a concepção sistêmica de família e de disfunção familiares, já solidamente rejeitados pelo Serviço Social.

Para aprofundamento do debate, apresentaremos algumas defesas para a inserção do/a assistente social na mediação familiar. A primeira e mais recorrente justificativa é a defesa que tanto a atividade mediação pode ser qualificada se realizada por assistentes sociais, como a profissão também se enriquece. Dessa forma, há uma aposta nas técnicas da mediação como uma forma de qualificar a atuação.

A mediação é um processo de trabalho viável por várias razões: é dada oportunidade às pessoas de dialogarem e decidirem sobre o conflito, assumindo suas decisões, ou seja, não se imputa à figura dos profissionais de determinada área profissional ou ao magistrado as decisões que os próprios sujeitos poderão tomar [...]. Contribui para que reflitam em torno das causas sociais relacionadas à origem do conflito, e suas consequências no âmbito individual [...] (Fávero; Mazuelos, 2010, p. 61).

Contudo, existem diversas formas de compreender e concretizar a mediação. Toni (2017) defende que a perspectiva Waratiana11 ou transformadora por ser empenhada direcionada à emancipação, à cidadania, à democratização da justiça e do direito, e que, portanto, essa perspectiva coadunaria com as defesas do projeto profissional do Serviço Social, mesmo não desenvolvendo o que tal perspectiva entende por tais categorias que são tão polêmicas e debatidas no âmbito do pensamento crítico ${ }^{12}$. Vejamos: "Warat defende a cultura

11 Baseada nas ideias de Luiz Alberto Warat, tal perspectiva preza pelo respeito à alteridade, pela promoção da autonomia, pela busca da cidadania e dos direitos humanos, cujo sentimento $e$ sensibilidade são elementos necessários para desenvolver a emancipação dos indivíduos (grifos nossos) (Toni, 2017, p. 327).

12 Segundo tal autor, as práticas de mediação não são neutras porque é necessário "sentir o sentimento". O mediador deve se preocupar em intervir nos sentimentos das pessoas para ajudá-las a sentir os próprios sentimentos. 
da paz que combate a violência e afirma que a emancipação do indivíduo tem relação com o encontro consigo mesmo, desenvolvendo sentimentos como amor, cuidado e afeto" (Toni, 2017, p. 327). Ainda que não tenhamos um estudo aprofundado em torno de tal compreensão waratiana ou das demais perspectivas formativas em torno da mediação, aparentemente suas concepções sustentam questões já superadas no âmbito do debate teórico-metodológico no que tange ao trabalho e formação profissional.

No que caberia à contribuição da mediação para a profissão, para destacarmos um elemento, reforça-se a ampliação do debate e do trabalho com a "subjetividade na profissão". Cabe destacar que tal argumento - sempre presente nas defesas - tem como pressuposto a suposta impossibilidade da tradição marxista "dar conta da subjetividade".

Conforme nos chamou atenção Costa (2012), Lukács já realizou a crítica necessária à parte da tradição marxista que negligenciou o problema da individualidade na obra Para a Ontologia do Ser Social, que é capaz de sustentar uma compreensão da subjetividade a partir de premissas marxianas. Fazendo a crítica "tanto em relação ao marxismo vulgar que compreende os fenômenos sociais como derivações mecânicas das legalidades econômicas, quanto as proposições idealistas ao situarem estes fenômenos exclusivamente na esfera da subjetividade" (Costa, 2012, p. 14).

Trata-se de demarcar aqui uma leitura que foge a uma compreensão da subjetividade como parte psíquica imanente ao ser humano, de ordem natural, sem conexão entre subjetividade e realidade objetiva, na contramão de uma compreensão que reduz a subjetividade aos sentimentos, às sensações (defesa presente nos fundamentos da medição familiar). Nesse sentido, parece problemática a defesa de que a conciliação/ mediação pode enriquecer o Serviço Social e contribuir para avançarmos no debate sobre subjetividade.

As defesas também demarcam que as/os assistentes sociais atuando na mediação são capazes de, após análise das situações particulares, encaminhar os sujeitos para a rede socioassistencial buscando a "garantia de direitos":

Considera-se, entretanto, que o Serviço Social [...] pode fazer uso da mediação enquanto instrumento facilitador do diálogo, da escuta e da reflexão em torno da situação ou das situações provocadoras do conflito - que é o que vem à 
tona - na direção do conhecimento e do acesso e da garantia de direitos, fundamentais e sociais (Fávero; Mazuelos, 2010, p. 62).

A partir dos apontamentos de tais autoras e das supostas possibilidades que esse "novo campo" abre, uma pergunta deve ser feita: Não é possível que nossa atuação no sociojurídico garanta um atendimento qualificado que, partindo das condições concretas colocadas pelos sujeitos, busque dialogar, refletir sobre seus fundamentos, e as estratégias coletivas e individuais na busca também pela garantia de direitos? Seria a mediação necessária para efetuar encaminhamentos dos/as usuários/as para políticas públicas? A nosso ver, isso já faz parte do processo de trabalho do Serviço Social.

Nessa direção cabe apontar a possibilidade de esvaziamento do método e dos aspectos teórico-metodológicos ao considerarem como metodologia a atividade. Afinal, não é possível em nosso atendimento garantir o "diálogo entre as pessoas", que as "famílias sejam orientadas", que possamos contribuir para que os indivíduos "reflitam sobre as causas sociais"? Acreditamos que tais questões podem e devem ser garantidas a partir do instrumental técnico operativo que historicamente a profissão vem construindo e que necessita ser qualificado ${ }^{13}$.

Nesse sentido, não estamos analisando se uma determinada técnica ou metodologia é compatível ou não com a profissão. Mas conforme chamou atenção o CRESS/SP, trata-se de constatar uma possível "legalização de possibilidades violadoras da regulamentação profissional”. Já que amparado pela lei da mediação também é prevista a chamada "desvinculação da profissão de origem”, ainda que o cargo ocupado seja de assistente social.

Assim, o/a Mediador/a de Conflitos poderá exercer uma "profissão dentro de outra profissão", abrindo inúmeras possibilidades de conflitos éticos e de

13 Cabe ressaltar que é comum nos trabalhos, conforme apontou Coelho (2016), o entendimento da mediação familiar com o mesmo sentido da categoria mediação na concepção marxiana. Conforme chama a atenção a autora a mediação na concepção marxiana "é uma categoria ontológica e reflexiva que cria e recria historicamente as relações sociais concretas”. A categoria marxiana de mediação é o aporte teórico que possibilita a articulação entre as diversas dimensões da vida social [...] (CRESS/SP, 2016, p. 39). 
competência profissional, inclusive perante as atribuições já consolidadas no âmbito de várias políticas públicas (Nota Técnica CRESS/SP, 2016. p. 27).

Outro argumento recorrente é o discurso da possibilidade de ampliação do quadro de vagas. Argumento contraditório, considerando que a resolução sobre a mediação surge como resposta exatamente às exigências do neoliberalismo, conforme demonstrou Hillesheim (2016). Ou seja, da necessária reestruturação produtiva, donde o discurso da modernidade do trabalho resulta na sobrecarga dos técnicos que já trabalham - pois não apresenta nenhum indicativo de concurso público ${ }^{14}$; e na ampliação do voluntariado, conforme prevê a lei, em relação aos mediadores extrajudiciais.

\subsection{Elementos centrais para uma crítica à defesa da mediação familiar}

Dentre as diversas questões que podem ser problematizadas como elementos que justificam a crítica, além dos já apresentados até aqui, destacaremos dois: I) o confronto aos fundamentos ético-políticos profissionais; II) a concepção do trabalho com famílias.

Um dos pontos mais preocupantes está relacionado aos códigos de ética profissionais. Como já apresentamos, os/as mediadores/as possuem código de ética próprio. Conforme já sinalizou a nota técnica do CRESS/SP, diversos problemas surgem desse conflito. Devido à possibilidade de violação do código de ética.

[...] Conforme consta no Código de Ética dos/as mediadores/as e Conciliadores, as atividades destes profissionais podem sofrer sanções em caso de confirmadas determinadas atitudes que contrariam este Código de Ética. Porém, considerando a possibilidade de exercício concomitante das profissões, o inverso não é observado, ou seja, o/a mediador/a e conciliador não sofrerão penalidades se violarem o código de ética de sua profissão de origem, partindo

14 Sobre a precarização do trabalho das assistentes sociais no Judiciário, ver: Colombi, 2016. 
do pressuposto de que estejam desvinculados das mesmas (Nota Técnica CRESS/SP, 2016, p. 46).

O conflito entre o código de ética profissional do Serviço Social e o código de ética do mediador acarreta sérios problemas no que tange às competências e atribuições para a/o profissional que assume tal atividade. Como seguir os valores colocados pela mediação perante a pauta das opressões? De que perspectiva de totalidade se fala quando se deslocam as opressões - no âmbito particular — para os próprios sujeitos decidirem? As determinações estruturais entram onde quando a melhor estratégia é o consenso?

Nessa direção ainda, a defesa dos princípios de imparcialidade e neutralidade - para elencarmos só dois - vão à contramão do que defende o projeto profissional crítico, materializado no código de ética profissional, pois são princípios incabíveis numa atuação profissional essencialmente política, como já nos alertou Iamamoto (2013). Esse ponto relacionado com temas que transversalizam a realidade das famílias como as relações sociais de classe, raça, etnia, sexo/gênero, sexualidade, geração, entre outros, não possibilita a defesa de tais princípios. Dito de outra forma: o enfrentamento histórico construído pela profissão, tendo como marco o código de ética profissional, não possibilita o trato das explorações-opressões vivenciadas pelos indivíduos e suas famílias a partir de princípios como o da conciliação/mediação: "Ora, se é dever do/a assistente social atuar na alteração da correlação de forças institucionais, como é possível esse mesmo profissional se colocar num patamar de consensualidade, neutralidade ou imparcialidade perante o conflito apresentado?" (CRESS/SP, 2016, p. 48).

Tal defesa corrói por dentro um dos maiores ganhos do processo de reconceituação/renovação, afetando diretamente a direção social construída, qual seja: a desmistificação da pretensa neutralidade da ação profissional, permitindo situar o Serviço Social no contexto das relações sociais. Conforme sinalizou Netto (2015), a dimensão política é algo inerente à profissão, no entanto, anterior ao processo de renovação, a profissão construía sua imagem como neutra, exatamente para mascarar a direção conservadora. Por isso, o risco no tempo presente da "politização à direita". Diante do cenário que 
a conjuntura brasileira vivencia - e nesse sentido a profissão - enfrentar a defesa da neutralidade como princípio ético é enfrentar a retomada do conservadorismo.

O segundo elemento diz respeito ao debate sobre famílias. Como parte e expressão da discussão sobre famílias no âmbito da profissão, as mesmas aparecem desvinculadas da particularidade que assumiu no sistema do capital. Há uma percepção da família como responsável pela manutenção da vida do ponto de vista: a) da subsistência física; b) da dimensão psíquica; c) do espaço de tranquilidade e amparo (afetividade). A ausência do entendimento de tal instituição a partir de sua contraditoriedade tem levado a considerá-la como tipo ideal, defendendo que a mesma pode ser identificada apenas a partir da tríade: diálogo, amor e compreensão.

A ênfase é na família como unidade em si mesma ou como unidade de tratamento, com destaque na dinâmica interna, a partir da possibilidade de êxito ou fracasso da vida familiar, sem levar em conta a relação com a sociabilidade. Trata-se do reflexo presente na profissão - expressão da ciência burguesa - que elege a família como a instituição de referência para compreender a realidade concreta, e nesse sentido, ocorre um deslocamento das determinações estruturais do sistema do capital, das classes sociais para o foco nas "relações", donde conforme sabemos só podem resultar na psicologização, moralização e responsabilização dos indivíduos e suas famílias (Horst, 2018).

Nessa direção, é importante demarcarmos que o Judiciário tem uma relação histórica com as famílias, afinal, as mesmas são acionadas por ele a "cumprir as normas". É sob essa ótica que precisamos nos atentar ao destacar a justiça classista. Esse espaço pode ser o lugar de reafirmar direitos, mas ao mesmo tempo, de exigências moralistas, consonantes com a sociabilidade. Cabe ainda ressaltar, conforme indicou o CRESS/SP, que o preenchimento de quadros na área da Mediação familiar seja possibilitado pela criação exclusiva de cargos para mediadores/as ${ }^{15}$.

15 O CRESS/SP também indicou que os bacharéis em Serviço Social que decidirem pelo exercício profissional de mediadores, que não ativem ou cancelem a inscrição nos respectivos 
Nessa direção, consideramos que posturas conciliatórias alijadas da luta de classes, das opressões, das desigualdades sociais, que atomizam os sujeitos não condizem com as escolhas profissionais consonantes com nosso projeto ético-político. Por isso, é nítida “[...] a preocupação em não colidir abertamente com o projeto ético-político - assim, "novos paradigmas" se apresentam como compatíveis com ele e até como necessários complementos para fazê-lo avançar" (Netto, 2016, p. 67).

A partir do exposto, é urgente reafirmar a defesa de um projeto profissional que dê o norte para uma atuação crítica, competente técnica, teórica e politicamente. Nesse sentido, na área sociojurídica, os profissionais devem “[...] trazer aos autos de um processo ou a uma decisão judicial os resultados de uma rica aproximação à totalidade dos fatos que formam a tessitura contraditória das relações sociais nessa sociedade, em que predominam os interesses privados e de acumulação [...]" (Borgianni, 2013, p. 423).

\section{Considerações finais}

As reflexões do presente texto sintetizam preocupações com o exercício profissional diante das investidas conservadoras. Não temos a pretensão de esgotar o debate e por isso a ênfase em alguns dilemas da inserção profissional em tal atividade. Cabe destacar a diversidade de posicionamentos presente nas produções sobre a temática que nem sempre se colocam na defesa integral do que advogam a formação e as normativas da mediação. A nosso ver, tais ponderações exigem maior atenção e reflexões em torno dos argumentos favoráveis e contrários à nossa inserção em tal atividade.

De modo geral, as defesas pela inserção do/a Assistente Social na mediação familiar, giraram em torno das possibilidades dessa atividade qualificar a atuação, de garantir direitos dos/as usuários/as e ampliar as vagas

conselhos, considerando que a intervenção como mediador não corresponde às atribuições do Serviço Social. 
para a profissão. No entanto, a partir da análise feita, não vislumbramos elementos que consolidassem tais defesas.

Por fim, gostaríamos de apontar um último elemento cujos estudos futuros precisam enfrentar: as manifestações endógenas atualizadas. Os trabalhos não partem das transformações societárias em curso e seus impactos no judiciário. Tomam a mediação/conciliação como atividades em si mesma ${ }^{16}$. O que não possibilita, a nosso ver, aportar as tendências privatizantes, de terceirização, precarização e avanço do voluntariado, inerentes a tal atividade. Nesse sentido, consideramos que enfrentar tal atividade nos exige minimamente três tarefas:

1. Analisar as implicações da atual crise do capital para o Poder Judiciário, com vistas a identificar as "novas" demandas colocadas para a profissão;

2. Avançar no debate sobre o complexo social do direito, com vistas a garantir uma crítica ontológica-histórica que aponte sua função social, limites e contradições;

3. Aprofundar a relação entre família e sua particularidade no capitalismo, com vistas a negar sua naturalização, e a reedição de práticas centradas em dinâmicas individuais, focalizadas, sustentadas por diversas bases teóricas.

É preciso coletivamente pensar estratégias que garantam respostas às exigências colocadas para o trabalho profissional - interpretando as necessidades sociais que geram as demandas e a que projeto societário se vincula as requisições institucionais - a partir dos fundamentos teórico-metodológicos e ético-políticos construídos nos últimos 40 anos, que poderão nos auxiliar na construção de respostas alternativas às requisições neoconservadoras.

16 Em um dos trabalhos, por exemplo, Toni (2017) reconhece que o Serviço Social é demandado para desenvolver tal atividade justamente pelo reconhecimento do seu trabalho, principalmente por parte dos juízes. 


\section{Referências}

BORGIANNI, E. Para entender o Serviço Social na área sociojurídica. In: Revista Serviço Social e Sociedade. São Paulo, n. 115, p. 407-442, jul./set. 2013.

COELHO, M. A. Parecer analítico do posicionamento preliminar sobre Serviço Social e mediação - CRESS/SP. In: Posição preliminar sobre serviço social e mediação de conflitos: nota técnica. São Paulo: CRESS/SP. 9a Região - Conselho Regional de Serviço Social do Estado de São Paulo, jun. 2016.

COLOMBI, B. L. P. A precarização do trabalho em foco: rebatimentos para os assistentes sociais do Judiciário. In: Serv. Soc. Soc., São Paulo, n. 127, p. 574-586, set./dez. 2016.

CONSELHO NACIONAL DE JUSTIÇA. Curso de Mediação de Família. Brasília, 2015. Disponível em: http://www.cnj.jus.br/files/conteudo/destaques/arquivo/2015/03/e82c5dcf9bcbefc1328225ce122dc98c.pdf. Acesso em: 9 de fev. de 2019.

CONSELHO, R. S. S. P. Posição preliminar sobre serviço social e mediação de conflitos: nota técnica. São Paulo: CRESS/SP. 9a Região - Conselho Regional de Serviço Social do Estado de São Paulo, jun. 2016.

COSTA, G. M. Indivíduo e Sociedade. Sobre a teoria da personalidade em Georg Lukács. São Paulo: Instituto Lukács, 2012.

FÁVERO, E. T. O Serviço Social no Judiciário: construções e desafios com base na realidade paulista. In: Revista Serviço Social e Sociedade. São Paulo, n. 115, p. 508-526, jul./set. 2013.

. Serviço Social no Sociojurídico: requisições conservadoras e resistências na defesa de direitos. In: Revista Serviço Social e Sociedade. São Paulo, n. 131, p. 51-74, jan./abr. 2018.

MAZUELOS, E. P. Q. Serviço Social e acesso à justiça - reflexões com base na prática de mediação familiar. Revista Serviço Social \& Saúde. UNICAMP Campinas, v. IX, n. 9, Jul. 2010.

HILLESHEIM, J. Conciliação trabalhista: ofensiva sobre os direitos dos trabalhadores na periferia do capitalismo. Tese de Doutorado - Programa de Pós-Graduação em Serviço Social (PPGSS/UFSC). Florianópolis, 2015.

HORST, C. H. M. Família, Marxismo e Serviço Social: ‘desvendando o invólucro místico'. Tese Defendida no Programa de Pós-Graduação em Serviço Social da Universidade Federal de Santa Catarina. 2018.

IAMAMOTO, M. V. Renovação e Conservadorismo no Serviço Social - Ensaios Críticos. 12. ed. São Paulo: Cortez, 2013.

LUKÁCS, G. Para uma ontologia do ser social II. São Paulo: Boitempo editorial, [1981] 2013.

NETTO, J. P. Transformações societárias e Serviço Social - Notas para uma análise prospectiva da profissão no Brasil. Revista Serviço Social e Sociedade, n. 50, ano XVII, abril de 1996.

Capitalismo Monopolista e Serviço Social. 8. ed. São Paulo: Cortez, 2011. 
NETTO, J. P. Para uma história nova do Serviço Social no Brasil. Serviço Social no Brasil: história de resistências e de ruptura com o conservadorismo. Maria Liduína de Oliveira e Silva (Org.). São Paulo: Cortez, 2016.

PARIZOTTO, N. R. Violência doméstica de gênero e mediação de conflitos: a reatualização do conservadorismo. Revista Serviço Social \& Sociedade, São Paulo, n. 132, p. 287-305, maio/ago. 2018.

SARTORI, V. B. Direito e Socialismo? A atualidade da crítica de Marx e Lukács ao Direito. In: Revista Direito e Práxis, v. 5, n. 9, 2014, p. 277-300.

TONI, A. Serviço Social e Mediação Familiar. Tese de Doutorado — Programa de Pós-Graduação em Serviço Social da Universidade Federal de Santa Catarina, 2017.

VASCONCELOS, A. M. A/O Assistente Social na Luta de Classes - Projeto Profissional e Mediações Teórico-Práticas. 1. ed. São Paulo: Cortez, 2015.

\section{Sobre os autores}

Claudio Horst - Professor no Departamento de Serviço Social.

E-mail: claudiovasques1@hotmail.com

EMIlly Marques Tenorio - Assistente social.

E-mail: emillypmarques@gmail.com 